\title{
Heterogeneous Associative Plasticity in the Auditory Cortex Induced by Fear Learning - Novel Insight Into the Classical Conditioning Paradigm
}

\author{
Ondrej ZELENKA ${ }^{1,2}$, Ondrej NOVAK ${ }^{1,3}$, Aneta BRUNOVA ${ }^{1}$, Josef SYKA $^{1}$ \\ ${ }^{1}$ Department of Auditory Neuroscience, Institute of Experimental Medicine of the Czech Academy \\ of Sciences, Prague, Czech Republic, ${ }^{2}$ Third Faculty of Medicine, Charles University, Prague, \\ Czech Republic, ${ }^{3}$ Department of Physiology, Second Faculty of Medicine, Charles University, \\ Prague, Czech Republic
}

Received August 13, 2020

Accepted February 18, 2021

Epub Ahead of Print May 12, 2021

\begin{abstract}
Summary
We used two-photon calcium imaging with single-cell and celltype resolution. Fear conditioning induced heterogeneous tuning shifts at single-cell level in the auditory cortex, with shifts both to $\mathrm{CS}^{+}$frequency and to the control CS stimulus frequency. We thus extend the view of simple expansion of $\mathrm{CS}^{+}$tuned regions. Instead of conventional freezing reactions only, we observe selective orienting responses towards the conditioned stimuli. The orienting responses were often followed by escape behavior.
\end{abstract}

\section{Key words}

Auditory cortex • Plasticity - Fear conditioning - Single-cell resolution • Interneurons

\section{Corresponding author}

O. Novak, Department of Physiology, Second Faculty of Medicine, Charles University in Prague, Plzenska 221, Prague 150 00, Czech Republic. E-mail: Ondrej.novak@lfmotol.cuni.cz

\section{Introduction}

The sensory cortex is able to modify its function based on preceding experience in order to optimize processing of behaviorally relevant stimuli. In the auditory cortex (AC), functional reorganization is induced by various types of learning (Pienkowski and Eggermont 2011, Syka 2002) and receptive fields can be dynamically retuned over multiple timescales (Fritz et al. 2003, Froemke and Schreiner 2015, Winkowski et al.
2013, Yin et al. 2014). There is expanding evidence that information processing in the $\mathrm{AC}$ is flexibly and adaptively shaped by learned significance of sounds and their behavioral context (Kato et al. 2015, Kuchibhotla et al. 2017, Marlin et al. 2015, Pachitariu et al. 2015, Rothschild et al. 2013, Schreiner and Polley 2014, Winkowski et al. 2013). Resulting learning-related changes in synaptic strength and cortical dynamics are followed by improved perception and behavioral performance (Bathellier et al. 2012, Froemke et al. 2013, Sarro et al. 2015). Associative plasticity in the AC can be elicited both by aversive and appetitive conditioning (Weinberger 2007). After the conditioning, neurons have been repeatedly reported to retune their best frequencies towards or at the frequency of the conditioned stimulus (Bakin and Weinberger 1990, Diamond and Weinberger 1986, Edeline et al. 1993, Ji and Suga 2007, Kraus and Disterhoft 1982, Recanzone et al. 1993). At global scale, associative learning leads to tonotopic map expansion with overrepresentation of the frequency of the conditioned stimulus. The map expansion is correlated with increased motivation and enhanced discriminability (Bieszczad and Weinberger 2010, Polley et al. 2006, Rutkowski and Weinberger 2005). Similar receptive field plasticity was found using stimulation of nucleus basalis or ventral tegmental area instead of an unconditioned stimulus (Bao et al. 2001, Kilgard and Merzenich 1998). However, the aforementioned often-cited results describing receptive field and map plasticity after the 
conditioning were obtained mostly using multi-unit recordings or single unit recordings in low numbers of neurons. The former methods sum the activity of higher number of cells and the latter are inherently biased towards larger, more active or more strongly responding cells (Harris et al. 2016). Thus, the nature of the plasticity as described by classical electrophysiological approaches has been unclear at the population-level. Intriguingly, a recent study found a contrast enhancement following exposure to behaviorally important ultrasonic stimuli without any corresponding map expansion in the AC (Shepard et al. 2016). To better understand the exact nature and mechanisms of learning-induced plasticity at population level, experiments using functional optical in vivo imaging that is capable of single-cell and cell-type resolution are needed (Chen et al. 2013, Svoboda and Yasuda 2006). We used chronic two-photon calcium imaging in transgenic mice to study receptive field plasticity induced by fear conditioning. We measured tonal responses in neuronal populations in the layer II/III of core AC with single-cell resolution. Because cortical inhibition, especially in supragranular layers, is essential for receptive field formation, plasticity and learning in the AC (Froemke et al. 2007, Letzkus et al. 2011, Li et al. 2014b, Liu et al. 2007, Sarro et al. 2015), we also study the major subclass of cortical interneurons, parvalbumin (PV) cells together with principal cells (tdTomato').

Here we show heterogeneous population plasticity elicited by fear conditioning. On single-neuron level, we observed a substantial fraction of neurons that retuned towards $\mathrm{CS}^{-}$control stimulus, challenging the typical description of the area retuning in the classical two-stimuli fear conditioning experiments. PV interneurons did not manifest significantly different behavior from the principal cells. Further, using a more detailed approach for analyzing the behavioral responses after fear learning, we observed selective orienting responses towards the conditioned stimulus. The selective attention was followed by escape behavior combined with subsequent freezing reactions to form dynamic defense patterns (Blanchard 2017).

\section{Methods}

Animals

For calcium imaging experiments we used PV2PA-Cre/flex-tdTomato mice $(\mathrm{n}=5$, Jackson Stock $\# 008069$ crossed with \#007908) for selective labeling of PV cells with a red fluorescent protein tdTomato. For behavioral experiments, we used $\mathrm{C} 57 \mathrm{Bl} / 6 \mathrm{~J}$ mice $(\mathrm{n}=15$; 5 in each group with different conditioning current amplitude). Young adult mice (6-12 weeks) of both sexes were used. The animals were provided with food and water ad libitum and housed on $12 \mathrm{~h}$ dark/light cycle. All procedures were approved by Institutional Animal Care and Use Committee at Institute of Experimental Medicine, Czech Academy of Sciences. The procedures were carried out in accordance with the relevant guidelines and regulations.

\section{Cranial window surgery and viral transduction}

Mice were anesthetized with isoflurane (1-1.5\%) and placed on a heating pad $\left(38^{\circ} \mathrm{C}\right)$. A chronic cranial window was implanted over the right auditory cortex. Initially, a midline incision was made and skin margins were attached to the skull by cyanoacrylate (UHU Supergel). A metal bar was used for head immobilization. After resecting right temporal muscle, a craniotomy over the auditory cortex was gently performed, leaving dura intact. Following the craniotomy, small volumes $(20-40 \mathrm{nl})$ of AAV1.syn.GCaMP6s vectors (Penn Vector Core; titer $5.10^{11} \mathrm{gc} / \mathrm{ml}$ ) were microinjected at very slow application speed $(\sim 25 \mathrm{nl} / \mathrm{min})$ using a pulled glass capillary (tip $5-10 \mu \mathrm{m}$ ) at multiple ( 10) locations to the depth of $250 \mu \mathrm{m}$ bellow dura. The craniotomy was covered with a small glass coverslip ( $3 \mathrm{~mm}$ diameter) and sealed using cyanoacrylate. The rate of GCaMP6s expression was monitored by epifluorescence imaging, reaching optimal levels for twophoton imaging in 3-4 weeks.

\section{Two-photon calcium imaging and data analysis}

Calcium data were recorded using an Ultima IV two-photon microscope (Prairie Technologies) with a Chameleon Vision II laser (Coherent). The laser wavelength was set to $920 \mathrm{~nm}$ for all measurements. Mice were anesthetized with isoflurane (0.8-1\%). GCaMP6s calcium signals were recorded using a LUMPLFLN 20XW objective (NA $=0.95$, Olympus) from depth of 150-300 $\mu \mathrm{m}$ below pia in a full-frame scanning mode (sampling frequency $\sim 5 \mathrm{~Hz}$ ). The core auditory cortex was localized using one-photon epifluorescence imaging with low-magnification objective $(4 \times)$ as cortical areas showing tonotopically organized responses to tonal stimuli. The areas were compared to the map of the mouse auditory cortex fields (Issa et al. 2014). The data were processed with TwoPhoton Processor software package in MATLAB (Novak 
et al. 2016, Tomek et al. 2013) using peeling algorithm for spiking activity inference (Grewe et al. 2010). Local neuropil signal was subtracted. Before the processing, data were semi-automatically segmented using custom written scripts in MATLAB. Only fields of view containing less than $5 \%$ of neurons with GCaMP6 filled nuclei were included in the dataset, as overexpression of GCaMP6 interferes with neuronal function and can influence response selectivity (Chen et al. 2013). Tuning curves (TC) were computed by summing responses for a given frequency over all intensities. Best frequency was defined as a frequency corresponding to the peak response of the TC. For the purpose of the comparison of tuning before and after the fear conditioning, only neurons significantly responding both before and after the conditioning were included in the dataset (significant increase in evoked activity compared to preceding spontaneous activity, $500 \mathrm{~ms}$ response window, Wilcoxon signed-rank test, $\mathrm{p}<0.05$ ). The receptive fields were measured two days before and two days after the fear conditioning.

Acoustic stimulation in two-photon imaging experiments

Acoustic stimuli waveforms were created in MATLAB, amplified by Transiwatt 140P amplifier and delivered from a TDT MF1 speaker (Tucker-Davis Technologies) positioned $15 \mathrm{~cm}$ from and pointing to the contralateral ear, and passed through a $7 \mathrm{~cm}$ wide opening in the heated pad. The speaker was calibrated using a B\&K 4939 microphone, a ZC0020 preamplifier, and a B\&K 2231 Sound Level Meter. The acoustic stimuli comprised pure tones (91 stimuli, 13 frequencies logarithmically spaced between $4-32 \mathrm{kHz}$ presented at seven intensity levels evenly spaced between 20-80 dB SPL, $5 \mathrm{~ms}$ linear ramps, $100 \mathrm{~ms}$ duration, $2000 \mathrm{~ms}$ interstimulus interval). In a small subset of experiments, we used acoustic stimulation with a finer frequency resolution (133 stimuli, 19 frequencies logarithmically spaced between $2-45 \mathrm{kHz}$ ). The stimuli were presented in a random order, with 7 repetitions of the stimulation battery. The inner microscope cage was insulated with sound absorbing foam. The laser power supply unit was placed in a custom-made noise-isolating chamber.

\section{Fear conditioning and behavioral testing}

Fear conditioning was performed in a Habitest cage (Coulborn Instruments). The conditioned stimulus $\left(\mathrm{CS}^{+}\right)$was an $8 \mathrm{kHz}$ pure tone ( $80 \mathrm{~dB}$ SPL, $3 \mathrm{~s}$ duration) associated with a foot shock $(1.0 \mathrm{~mA}$ intensity,
$1 \mathrm{~s}$ duration) applied during the last second of $\mathrm{CS}^{+}$. As a control unassociated stimulus $\left(\mathrm{CS}^{-}\right)$, we used a $16 \mathrm{kHz}$ pure tone ( $80 \mathrm{~dB}$ SPL, $3 \mathrm{~s}$ duration). Free-field stimuli (15 repetitions of both $\mathrm{CS}^{+}$and $\mathrm{CS}^{-}$in a random order, a random inter-stimulus interval in range of 20-40 s) were generated using Asus Xonar STXII sound card, amplified by Transiwatt 140P amplifier and delivered using a SS-LAC305ED speaker (Sony). The speaker was calibrated using the same devices as in the case of stimulation in two-photon imaging experiments. Conditioning and behavioral testing were conducted in different spatial contexts. Before the behavioral testing, the walls of the conditioning cage were replaced with ones with different pattern, the bar floor was covered with a safe solid floor and the cage was thoroughly cleaned before the conditioning and the training session ( $70 \%$ ethanol and $1.5 \%$ acetic acid, respectively). The behavior was registered using a full-HD video camera (HC-X900M, Panasonic, $25 \mathrm{fps}$ ) and assessed objectively by image tracing, using custom-written scripts in MATLAB. Before training, the metal bar on animal's head was labeled with a green and a red dot. The images were analyzed using RGB decomposition and single channel brightness thresholding, which allowed us to precisely determine current head position and direction. Orienting responses as a measure of selective attention (Bradley 2009) were calculated as absolute derivatives of head direction (time span $3 \mathrm{~s}$ before, $3 \mathrm{~s}$ during and $3 \mathrm{~s}$ after the presentation of $\mathrm{CS}^{+}$or $\mathrm{CS}^{-}$). To evaluate planar movement of the animal, we determined travelled Euclidean distance between each pair of subsequent frames.

In three groups of animals $(3 \times 5$ mice; without cranial window surgery) that underwent only conditioning and behavioral testing we used three different footshock currents $-0.5 \mathrm{~mA}, 1.0 \mathrm{~mA}$ and $1.5 \mathrm{~mA}$.

\section{Results}

Using calcium imaging in the AC, we measured tonal receptive fields (RFs) of neurons two days before and one day after the fear conditioning (Fig. 1). The conditioned stimulus $\left(\mathrm{CS}^{+}\right)$associated with footshock was an $8 \mathrm{kHz}$ pure tone and the control stimulus $\left(\mathrm{CS}^{-}\right)$ was a $16 \mathrm{kHz}$ pure tone (Fig. 1D). Based on the responses to pure tones during RFs measurements we sorted neurons based on their responsivity before and after the conditioning (see Methods). Out of 684 tdTomato not- 
expressing (tdTomato ${ }^{-}$) neurons we observed that 533 neurons $(78 \%$ ) were responsive both before and after the conditioning, 89 neurons (13\%) were responsive only before conditioning, 38 of neurons $(6 \%)$ started to be responsive after conditioning and 21 neurons (3\%) were unresponsive both before and after the conditioning. Out of 64 tdTomato-expressing $\mathrm{PV}^{+}$interneurons, 40 neurons (62\%) were responsive both before and after the conditioning, 10 neurons (16\%) were responsive only before conditioning, 8 of neurons (13\%) started to be responsive after conditioning and 6 neurons $(9 \%)$ were unresponsive both before and after the conditioning.

We recorded pure tones-evoked calcium transitions in the same set of the AC neurons both before and after the fear conditioning. Our datasets included $40 \mathrm{PV}^{+}$neurons and a group of neurons that did not express tdTomato in respective mouse crosses (here further termed as tdTomato cells, $n=533$ ). We did not genetically target principal cells directly, however, a vast majority of tdTomato ${ }^{-}$cells were of principal cell type. For example, according to (Tremblay et al. 2016), $>80 \%$ of neurons in $\mathrm{L} 2 / 3$ are principal cells and the rest are interneurons, $\sim 25 \%$ of $\mathrm{L} 2 / 3$ interneurons $(\sim 5 \%$ of all cells) are $\mathrm{PV}^{+}$tdTomato expressing interneurons. Thus more than $84 \%$ of tdTomato ${ }^{-}$( 80 out of 95 neurons tdTomato $^{-}$in every 100 neurons) cells belonged to excitatory principal cells and we further consider the group in this way.


$\mathbf{E}$

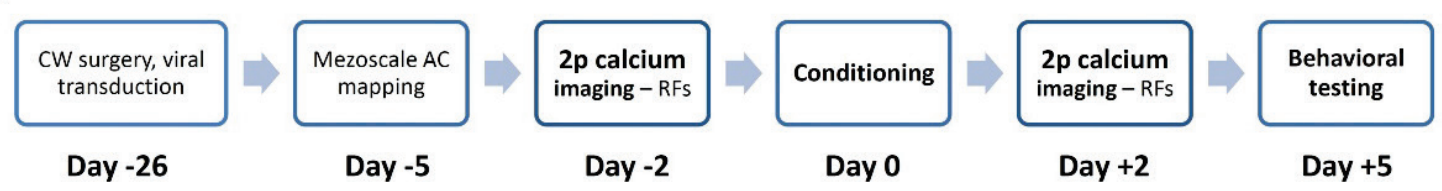

Fig. 1. Illustrative figure showing the key steps of the experiment. (A) Cranial window implanted over the right auditory cortex and the custom-made head holder. (B) Mesoscopic brightfield and epifluorescence image of the cranial window three weeks after the virus injection and cranial window implantation. (C) Two-photon image from layer 2/3 in the core auditory cortex of PV-Cre/tdTomato mouse. Neurons express GCaMP6s (green) and parvalbumin-expressing interneurons are co-labeled with tdTomato (red $\rightarrow$ orange). Insets typical single auditory neuron characteristics - peristimulation time histogram (upper) and a tonal receptive field (RF, lower). (D) Scheme of the fear conditioning protocol. (E) Diagram showing all consecutive steps of the experiment. 
Fear conditioning elicits heterogeneous tuning shifts in the auditory cortex

We determined tuning of individual neurons as best frequencies (BFs) calculated from their tuning curves (Fig. 2A). After the conditioning, we observed heterogeneous BF shifts. Unexpectedly, a substantial fraction of neurons shifted $\mathrm{BF}$ towards or at $\mathrm{CS}^{-}$ frequency (even if some of them were initially tuned to $\mathrm{CS}^{+}$frequency (Fig. 2A right, 2B). To describe the tuning shifts with respect to initial tuning, we plotted $\mathrm{BFs}$ of all neurons before the conditioning against the values after the conditioning (Fig. 3A) showing the heterogeneity of the retuning. Sizes of individual dots represent counts of neurons with the respective pre- and post-conditioning BFs. Interestingly, we found numerous unexpected combinations showing retuning towards $\mathrm{CS}^{-}(16 \mathrm{kHz})$. Despite the observed retuning heterogeneity, we observed a significant shift of the BFs average towards $\mathrm{CS}^{+}(0.4 \pm 0.1$ octave, $\mathrm{p}<0.001$, twotailed $t$-test); Figure 3B. We plotted mean tuning curves of the neurons before and after the conditioning (Fig. 3C). From these curves we observed significant decreases of activity at higher frequencies starting from $16 \mathrm{kHz}$ ( $\mathrm{CS}^{-}$frequency) above. Curves before (blue lines) and after (red lines) the conditioning are plotted in Figure $3 \mathrm{C}$ separately for excitatory cells (full line) and $\mathrm{PV}^{+}$cells (dotted line); error bars are SEM. We also analyzed the changes in numbers of neurons coding for individual BFs (Fig. 3D). Magenta lines represent the respective difference curves. From both group analyses, we were not able to conclude whether retuning towards $\mathrm{CS}^{-}$can or cannot be produced by chance.
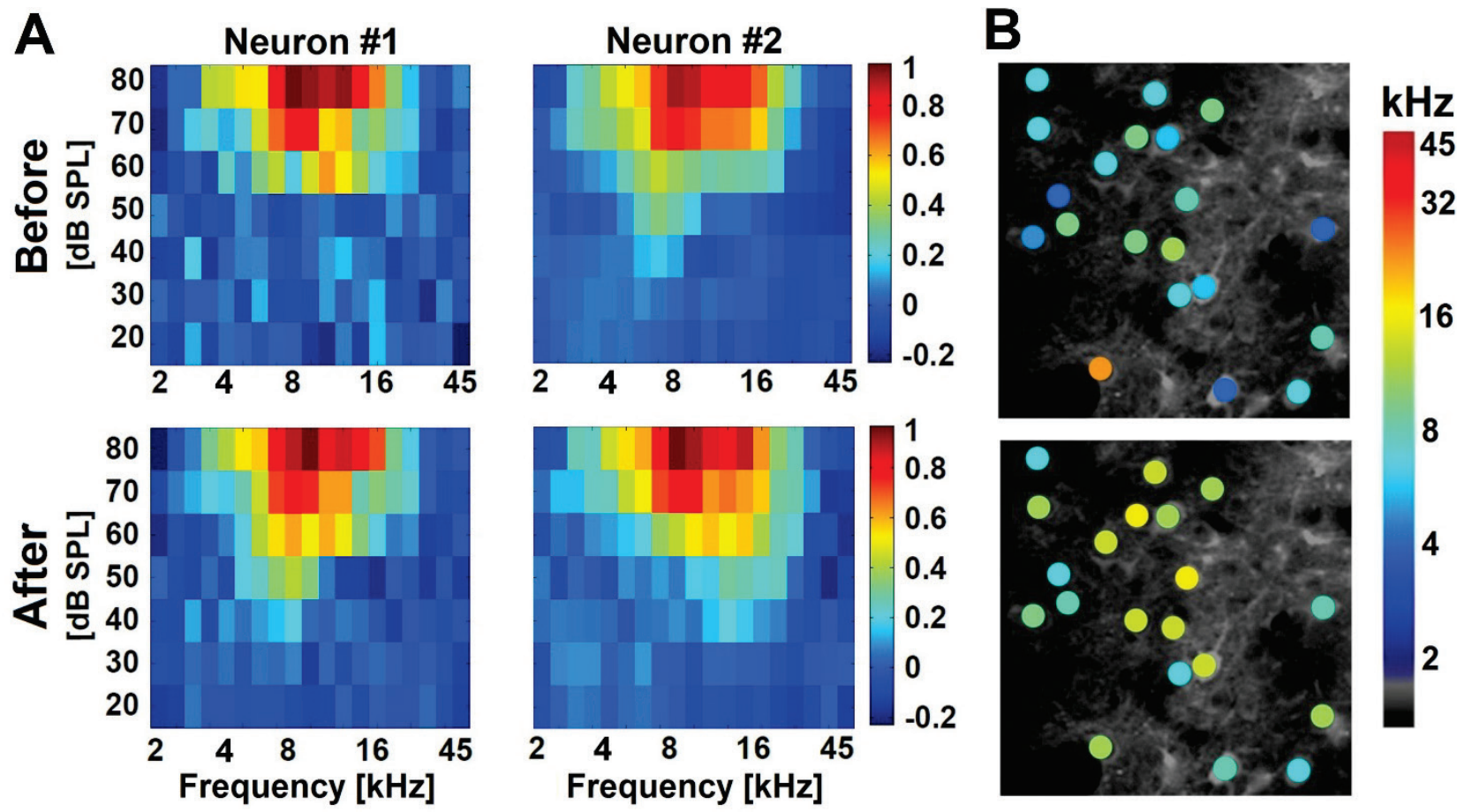

Fig. 2. Tuning of individual neurons before and after the fear conditioning. (A) Example of two neurons with different retuning following the fear conditioning protocol. Note that neuron \#2 retuned towards CS. (B) Tuning of a group of neurons expressing GCaMP6s calcium indicator. Identified neurons were color coded according to their best frequency; neurons with different retuning parameters turned up to be spatially intermingled.

Further analysis includes only neurons whose preconditioning $\mathrm{BF}$ belonged to the interval from the $\mathrm{CS}^{+}$up to the $\mathrm{CS}^{-}$, the interval of frequencies $<8 \mathrm{kHz}, 16 \mathrm{kHz}>$ $(\mathrm{n}=305)$. The motivation for this step was to avoid a possible bias as the distribution of our dataset was not symmetrical with respect to $\mathrm{CS}^{+}$and $\mathrm{CS}^{-}$frequencies. For example, many neurons with higher pre-conditioning BFs could be just "to far above $\mathrm{CS}^{+}$" to reach $\mathrm{CS}^{+}$if they receive similarly strong inhibitory unmasking around
$8 \mathrm{kHz}$ compared to neurons tuned closer to $\mathrm{CS}^{+}$before the conditioning. This could mask the tuning of some neurons to $\mathrm{CS}^{-}$in Figure 3B, C analysis. We plotted the histogram of BFs of those neurons and observed two peaks (Fig. 3E). To evaluate whether such two peaks can emerge randomly we took the conditioning-induced BFs changes of these neurons and assigned them randomly to the set of the neurons (Fig. 3F). 

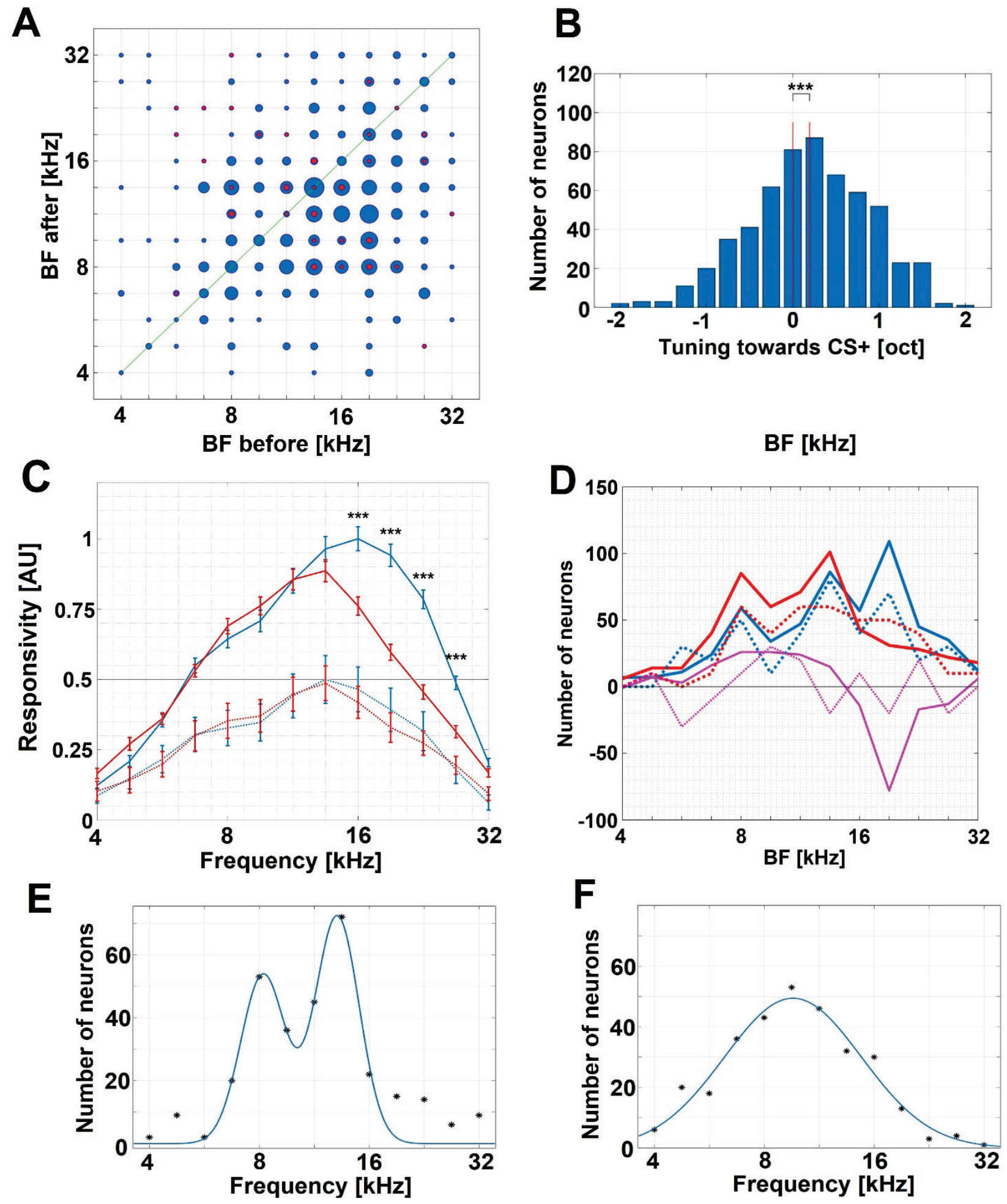

Fig. 3. Retuning of individual neurons after the fear conditioning overrepresents both $\mathrm{CS}^{+}$and $\mathrm{CS}^{-}$stimuli. (A) Plot of BFs of individual neurons before and after the conditioning: tdTomato neurons $\left(n=533\right.$, blue dots), $\mathrm{PV}^{+}$cells $(n=40$, red dots). The size of the spot represents multiplicity of the respective combination. (B) The mean BF of all neurons ( $n=573$ neurons) significantly moved to $\mathrm{CS}^{+}$stimulus, although the observed heterogeneity was large. (C) Responsivity of cortical neuron populations to pure tones defined as tone-evoked firing rate minus spontaneous firing rate; for each frequency the values were averaged across all intensities (Tuning curves). Curves before and after the conditioning (blue, red, respectively), tdTomato neurons' curves (solid) were normalized to 1 and $\mathrm{PV}^{+}$neurons' curves (dashed) were normalized to 0.5 for clarity in one figure. (D) Numbers of neurons with specific BFs before and after the conditioning. Color coding same as in the previous figure; difference curve (purple). Solid line tdTomato neurons, dashed line $\mathrm{PV}^{+}$neurons. (E) Distribution of BFs after conditioning for neurons with pre-conditioning BFs ranging from $8 \mathrm{kHz}$ to $16 \mathrm{kHz}(\mathrm{n}=305)$. Real data fitted with two-term Gaussian curve. Right peak in the panel shows tuning towards $\mathrm{CS}^{-}(16 \mathrm{kHz})$. (F) In data BFs before conditioning were changed with shuffled BF changes the right peak is not observable. 
As the group of neurons retuning towards $\mathrm{CS}^{-}$ represented a novelty, we further focused on their spatial arrangement with respect to neurons retuning towards $\mathrm{CS}^{+}$(Fig. 4). We classified the neurons into four categories - those which retuned away from both $\mathrm{CS}^{-}$and $\mathrm{CS}^{+}$(their BFs were further from both $\mathrm{CS}^{+}$and $\mathrm{CS}^{-}$after the conditioning than before) represented category (1) $(n=54)$ and were not further inspected. Neurons retuning towards $\mathrm{CS}^{+}$or keep $\mathrm{CS}^{+}$frequency - category (2) $(\mathrm{n}=132)$. Neurons retuning towards $\mathrm{CS}^{-}$or keep $\mathrm{CS}^{-}$frequency - category (3) $(\mathrm{n}=85)$. Neurons that did not changed their $\mathrm{BF}$ that had neither been $\mathrm{CS}^{+}$nor $\mathrm{CS}^{-}$frequency - category (4) $(\mathrm{n}=34)$. Examples of neurons belonging to these categories are depicted in Figure $4 \mathrm{~A}$ in real coordinates for one representative field of view (FOV).
A

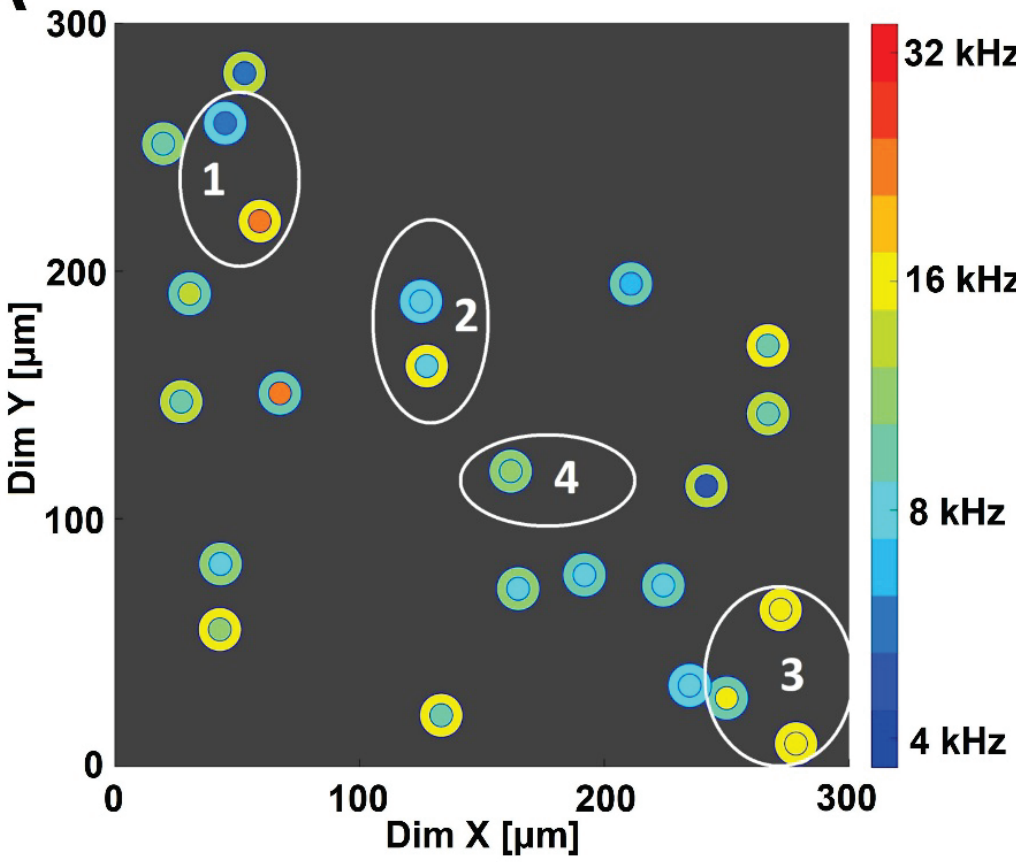

Distances N.cat3 $\rightarrow$ nearest N.cat3

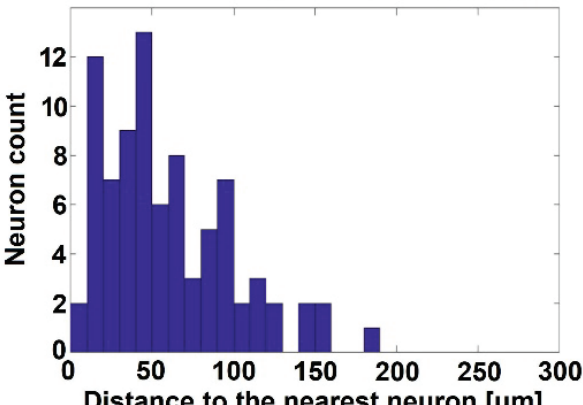

E
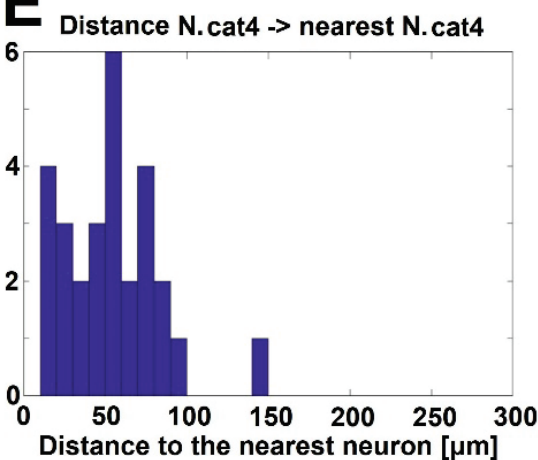

B Distances Neuron cat2 -> nearest N. cat3

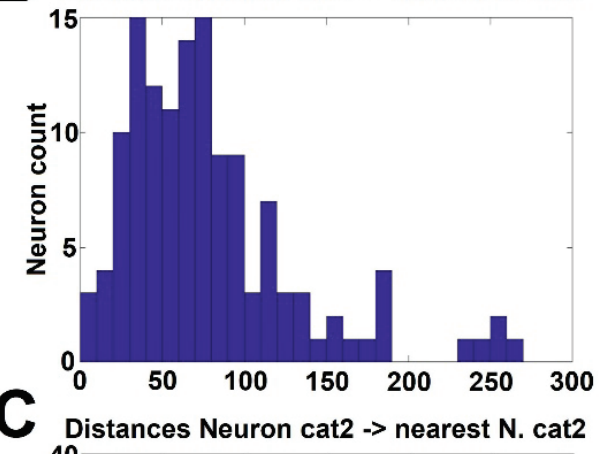
40

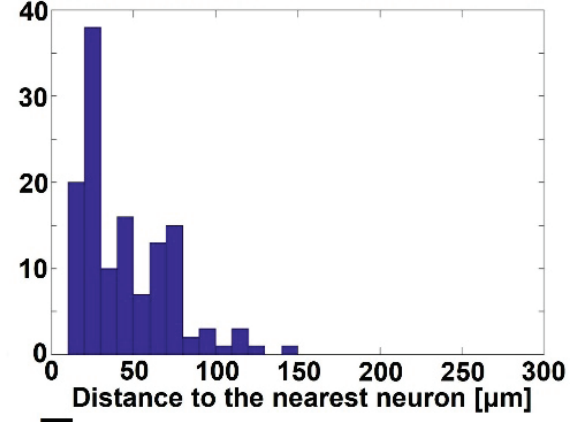

$\mathbf{F}$

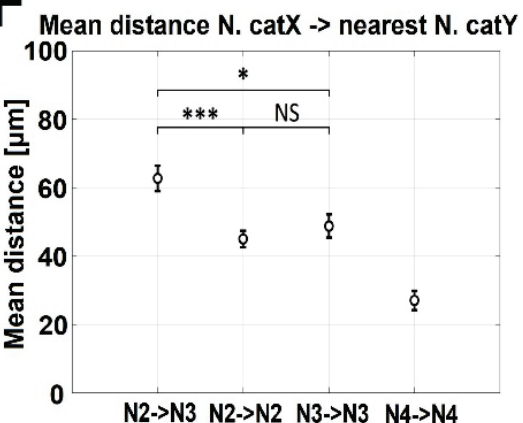

Fig. 4. Spatial analysis of individual neurons retuning. (A) Representative rectangular FOV (one out of sixteen) of $300 \mu \mathrm{m}$ side is depicted with individual neurons with pre-conditioning BFs belonging to the interval $<8 \mathrm{kHz} ; 16 \mathrm{kHz}>; \mathrm{n}=305$. Neurons are pictured here at their real positions and with outer diameters representing $12 \mu \mathrm{m}$. Neurons are color-coded according to their BFs before and after conditioning. Color of the outer ring represents BF before conditioning, central spot of the neuron represents BF after conditioning. Neurons were classified according to the character of their retuning after conditioning. Category (1) neurons $(n=54)$ retuned away from both $\mathrm{CS}^{+}$and $\mathrm{CS}^{-}$. Category (2) neurons $(n=132)$ retuned towards $\mathrm{CS}^{+}$. Category (3) neurons $(n=85)$ retuned towards CS. Category (4) neurons ( $n=34)$ did not change their BFs. B, Histogram of distances from single neurons of category (2) to their respective closest neighbors of category (3). (C, D, E) Same as in (B) but the distances were measured to the closest neuron belonging to the same category - category (2), category (3) and category (4), respectively. (F) Mean distances from (B, C, D, E) corrected for the number of neurons belonging to respective category; error bars represent standard error of the mean. Distances of neurons of different categories (category 2 and 3; first datapoint) tend to be larger than distances between neurons belonging to a same category $(p<0.0013$, two-tailed $t$-test, Bonferroni correction $\mathrm{n}=3$ ). 
To inspect spatial context of neurons belonging to a specific category, we calculated a distance from a neuron of such category to closest neurons of the same or different category. Histogram of distances of closest category (3) neurons to individual category (2) neurons is in Figure 4B. Histogram of distances of closest category (2) neurons to individual category (2) neurons is in Figure 4C. Histogram of distances of closest category (3) neurons to individual category (3) neurons is in Figure 4D. Histogram of distances of closest category (4) neurons to individual category (4) neurons is in Figure 4E. We compared such closest-neighbor distances (Fig. 4F) and observed that distances of neurons of different categories (category 2 and 3; first datapoint) were significantly larger than distances between neurons belonging to a same category ( $\mathrm{p}<0.0013$, two-tailed $t$-test, Bonferroni correction $\mathrm{n}=3$ ). Mean distances were corrected for the number of neurons belonging to such category. Despite this significant difference, mean closest-neighbor distance between neurons retuning towards $\mathrm{CS}^{+}$(category 2) and neurons retuning towards $\mathrm{CS}^{-}$(category 3), $63 \pm 3 \mu \mathrm{m}$, practically means that neurons of these two categories are spatially intermingled.

\section{Behavioral reactions to the conditioned stimulus}

To evaluate behavioral outcomes of the conditioning, we performed image tracing and objective behavioral analysis of each mouse in a different context arena with a safe floor. We tracked the colored nail polish marks on the headbar and calculated the position and orientation of the animal's head in each time bin (full HD camera frame). Tested animals showed various types of reaction upon $\mathrm{CS}^{+}$stimulus presentation (Fig. 5A). Upon presentation of $\mathrm{CS}^{+}$, we often observed two types of behavioral reaction: a period of an excessive movement (hyperlocomotion) and a period of orientation head movements (Fig. 5B, C). Interestingly, the extent of these reactions was inversely dependent on the current used during the conditioning. Presentation of $\mathrm{CS}^{+}$evoked reactive hyperlocomotion with maximal speed in the last second of $\mathrm{CS}^{+}$duration (maximum at $2.44 \mathrm{~s}$ after $\mathrm{CS}^{+}$ onset), i.e. during time corresponding to footshock delivery in the preceding training session. The hyperlocomotion as an escape behavior was followed by a suppression of movements, indicating freezing behavior (Fig. 5D, n=14 mice, 15 trials for $\mathrm{CS}^{+}$and 15 trials for $\mathrm{CS}^{-}$in each animal; mean z-scored speed; error bars are in S.E.M.).
The escape behavior was a selective reaction towards $\mathrm{CS}^{+}$, as we did not observe any speed increase after the presentation of $\mathrm{CS}^{-}$(Fig. 5D). Although freezing responses are often used as only indicators of fear learning, recent work demonstrated that mice can engage both active and passive defense behaviors during fear conditioning.

Orienting responses can be used as a measure of selective oriented attention. We computed changes in head angles as their derivatives. We observed shortlatency (with peak at $280 \mathrm{~ms}$ after $\mathrm{CS}^{+}$onset) orienting head movements as a selective reaction towards the $\mathrm{CS}^{+}$, which preceded the escape behavior. After the end of $\mathrm{CS}^{+}$ duration, the head movements were suppressed, again corresponding to freezing behavior (Fig. 5D, n=14 mice, 15 trials for $\mathrm{CS}^{+}$and 15 trials for $\mathrm{CS}^{-}$in each animal; mean z-scored absolute derivatives of head angles; error bars are in S.E.M). No orienting responses were induced by $\mathrm{CS}^{-}$presentation (Fig. 5D).

\section{Discussion}

Using two-photon calcium imaging in the auditory cortex, we studied learning-induced changes in population coding of sounds with single-cell resolution. In different neurons, both shifts towards the $\mathrm{CS}^{+}$and $\mathrm{CS}^{-}$ were present, which further expands the classical view of associative plasticity in the auditory cortex. Although tuning shift directions and magnitudes were heterogeneous at the level of individual cells, we observed significant tuning reorganization at the global scale, corresponding to many previous multi-unit electrophysiological studies. Neurons retuning towards the $\mathrm{CS}^{+}$, or to the $\mathrm{CS}^{-}$have closer neighbor of the same category as compared to closest neuron distances of units belonging to respective categories. Behaviorally, the plastic auditory cortex changes were accompanied by selective attention towards the conditioned stimuli.

Heterogeneous receptive field plasticity induced by associative learning

Our results describing retuning of individual auditory cortex neurons after fear conditioning complement the classical view of mesoscale auditory map expansion with concomitant best frequency shifts towards the frequency of $\mathrm{CS}^{+}$(McGann 2015, Weinberger 2007). Tuning shifts were heterogeneous on single-neuron level, with retuning both towards and from $\mathrm{CS}^{+}$frequency for most initial best frequencies. A hypothetic explanation 
can be that these different neurons form separate spatially intermingled subnetworks with different functions. This view corresponds to prevailing local tonotopic heterogeneity compared with global order at the macroscopic level (Bandyopadhyay et al. 2010, Kanold et al. 2014, Maor et al. 2016, Rothschild and Mizrahi 2015, Rothschild et al. 2010). A finding of diverse learning-related plasticity in multiple populations was also reported in visual cortex (Poort et al. 2015). Similar heterogeneous plasticity after auditory fear conditioning like in our study was recently described in amygdala, with both enhanced and suppressed responses to $\mathrm{CS}^{+}$and $\mathrm{CS}^{-}$in different cells after the learning (Grewe et al. 2017). Another difference with previous work is in recording depth, as the previous recordings were mostly done in layer IV/V and we recorded our data in layer II/III. Our approach reflects the associative plasticity more specifically, as layer II/III was identified as a major site of fear learning in the AC (Letzkus et al. 2011). Moreover, plasticity in intracortical inputs to $\mathrm{A} 1$ is best correlated with increased behavioral performance (Guo et al. 2013).
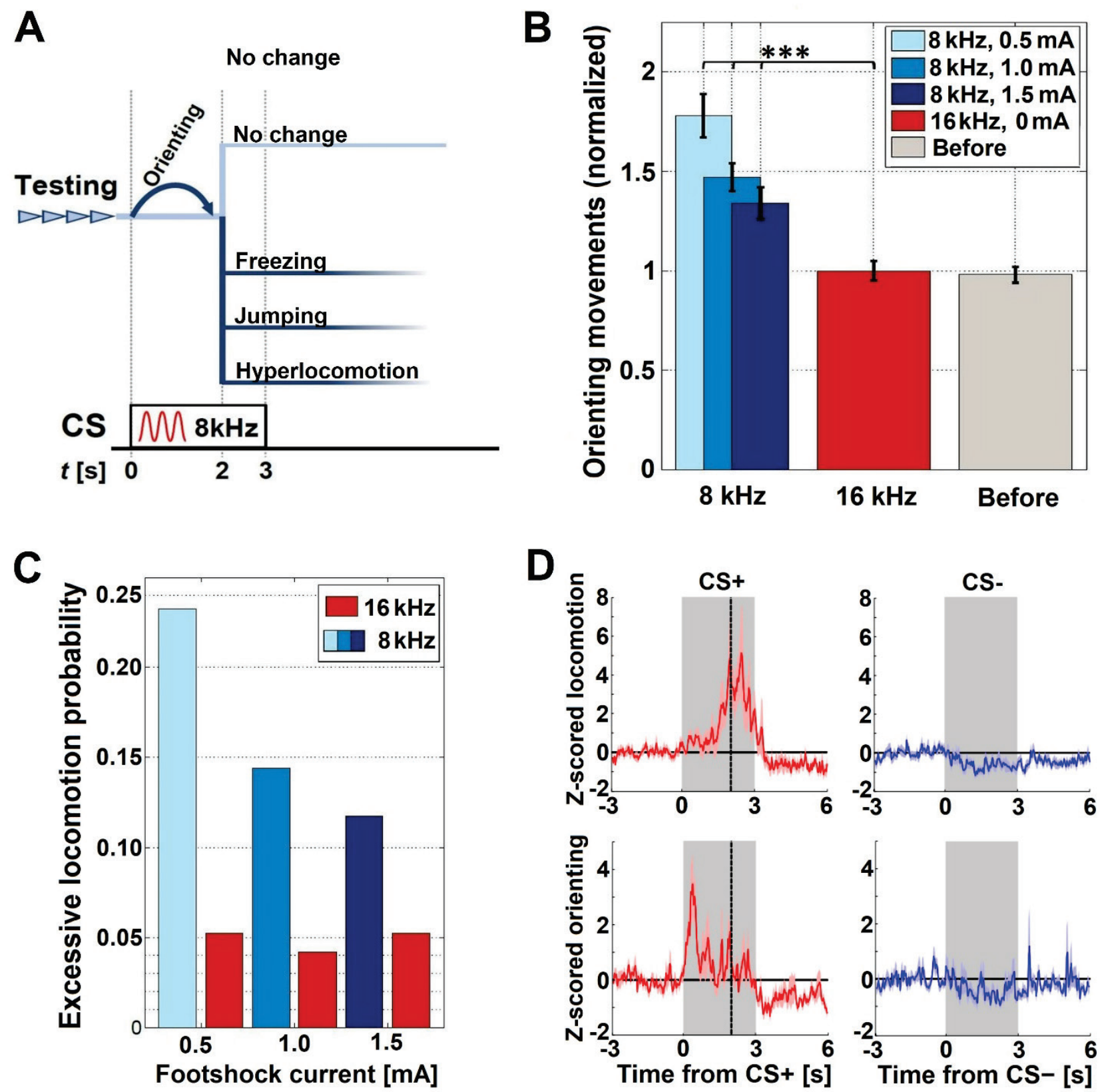

Fig. 5. Different behavioral responses to $\mathrm{CS}^{+}$and $\mathrm{CS}^{-}$were observed and evaluated. (A) Diagram of differential reactions to $\mathrm{CS}^{+}$with respect to the stimulus onset. (B) Head orienting movements were observed significantly more often in response to $\mathrm{CS}^{+}$. (C) Animal reacted to $\mathrm{CS}^{+}$presentation with excessive locomotion more often than upon $\mathrm{CS}^{-}$presentation. (D) Mean z-scored head orientating movements and locomotion with respect to the stimulus duration (gray area). 
We randomly presented $\mathrm{CS}^{+}$and $\mathrm{CS}^{-}$stimulus. We chose the conditioning with two tones $\left(\mathrm{CS}^{+}\right.$and $\left.\mathrm{CS}^{-}\right)$ as it was used in some of the classical works in the field (Antunes and Moita 2010, Diamond and Weinberger 1986). Based on the more traditional view of associative plasticity (Weinberger 2007), this is not expected to cause any shifts towards the $\mathrm{CS}^{-}$frequency, as $\mathrm{CS}^{-}$stimulus is not supposed to be associated with any behavioral relevance. On the contrary, a larger downregulation of neurons responding to frequencies around $\mathrm{CS}^{-}$frequency would be expected. However, using single-cell resolution we showed that the fraction of neurons retuning to $\mathrm{CS}^{-}$ can be as high as $28 \%$. In extracellular electrophysiological studies, these neurons could be masked by more numerous $\mathrm{CS}^{+}$retuning neurons (43\% of analyzed neurons in our dataset). It is possible that $\mathrm{CS}^{-}$stimulus might be associated with a period of "safety" and thus could partially gain positive value (Kong et al. 2014, Takemoto and Song 2019). Here we showed that neurons retuning to $\mathrm{CS}^{+}$and $\mathrm{CS}^{-}$are spatially intermingled and could, in principle, belong to different subnetworks with different functions (Rothschild and Mizrahi 2015).

A partial limitation of our study can be that we performed the recordings in mild isoflurane anesthesia, not in awake animals. Nevertheless, this fact does not limit the comparability to previous work, as most of the studies were also performed in anesthetized animals. Most importantly, receptive field shapes are not significantly influenced by anesthesia (Guo et al. 2012, Noda and Takahashi 2015). Anesthetics dramatically influence neuron response dynamics (Kato et al. 2015), which were due to lower achievable laser-scanning speed not studied in our work.

Specific stereotypical circuits driving associative plasticity in adult mice have been identified in last ten years. Both carrying information in a bottom-up direction (Letzkus et al. 2015, Letzkus et al. 2011) to various brain areas including amygdala and cortex, or associative circuits connecting higher/related cortical areas to primary cortices in a top-down direction (Lee et al. 2013, Zhang et al. 2014). The central role in all these circuits is played by vasointestinal peptide-expressing (VIP) inhibitory interneurons that specialize in inhibiting of inhibitory (Krabbe et al. 2019, Pi et al. 2013) cells and thus transiently increasing the excitability of local excitatory cells producing a time window for enhanced plasticity. VIP $^{+}$interneurons target mainly somatostatinexpressing $\left(\mathrm{SST}^{+}\right)$interneurons and to a smaller extent also $\mathrm{PV}^{+}$interneurons (Jiang et al. 2015). It could be hypothesized that such circuit can also adjust receptive fields of $\mathrm{SST}^{+}$interneurons that in turn highly influence receptive fields of cortical excitatory neurons (Lakunina et al. 2020). In our experiments we observed that after conditioning $\mathrm{SST}^{+}$interneurons show opposite tuning shift compared to excitatory neurons (unpublished data).

We did not find any principal differences in retuning of $\mathrm{PV}^{+}$interneurons as compared to the rest of the neurons (mainly pyramidal cells). Such result is not surprising concerning one of their main roles in cortical circuits where they serve with feedforward inhibition and regulate gain and timing (Atallah et al. 2012, Kepecs and Fishell 2014). To keep such purpose workable it is expedient to follow the tuning curves of the pyramidal neurons (Cohen and Mizrahi 2015, Li et al. 2014a, Li et al. 2014b).

Learning-induced plasticity and its relation to selective attention

Our behavioral data from head orientation tracking show selective orienting responses towards the conditioned stimuli. Both the learned significance of auditory stimuli and the rules for attentional selection are encoded in the auditory cortex (Fritz et al. 2010, Kato et al. 2015, Moczulska et al. 2013) together with upstream brain areas, especially frontal association cortex (Lai et al. 2012, Nakayama et al. 2015, Winkowski et al. 2013). Importantly, phasic cholinergic activation is necessary for associative learning (Letzkus et al. 2011) and a direct link between cholinergic reinforcement signals and auditory attention was demonstrated (Hangya et al. 2015). Consequently, the flow of information through cortical microcircuits can be adaptively gated by behavioral demands and modulated by top-down salience of the stimuli. The acquired salience biases selective auditory attention (Fritz et al. 2010, Lakatos et al. 2013, Polley et al. 2006, Rodgers and DeWeese 2014). Therefore, the representational plasticity in the auditory cortex can hypothetically pose a link between memory and selective auditory attention. The resulting behavioral adaptiveness is obvious, as it is behaviorally important both to remember threat-predicting stimuli as well as to pay attention towards them in future encounters.

\section{Conflict of Interest}

There is no conflict of interest. 


\section{Acknowledgements}

We thank Vit Vrsnik for technical assistance during the behavioral experiments. This work was supported by the Grant Agency of Charles University (GAUK 408313, GAUK 698217, PRIMUS/19/MED/03) and by the Grant Agency of the Czech Republic (18-09692S).

\section{Author contributions}

O.Z. designed experiments. O.Z., O.N., and A.B. performed experiments. O.Z. and O.N. analyzed data. O.Z. and O.N. prepared figures. O.Z., O.N. and J.S. interpreted results and wrote the manuscript. J.S. supervised the research. All authors except O.Z. $(\dagger 01 / 2018)$ reviewed the final manuscript.

\section{References}

ANTUNES R, MOITA MA: Discriminative auditory fear learning requires both tuned and nontuned auditory pathways to the amygdala. J Neurosci 30: 9782-9787, 2010. https://doi.org/10.1523/JNEUROSCI.1037-10.2010

ATALLAH BV, BRUNS W, CARANDINI M, SCANZIANI M: Parvalbumin-expressing interneurons linearly transform cortical responses to visual stimuli. Neuron 73: 159-170, 2012. https://doi.org/10.1016/j.neuron.2011.12.013

BAKIN JS, WEINBERGER NM: Classical-conditioning induces CS-specific receptive-field plasticity in the auditorycortex of the guinea-pig. Brain Res 536: 271-286, 1990. https://doi.org/10.1016/0006-8993(90)90035-A

BANDYOPADHYAY S, SHAMMA SA, KANOLD PO: Dichotomy of functional organization in the mouse auditory cortex. Nat Neurosci 13: 361-368, 2010. https://doi.org/10.1038/nn.2490

BAO SW, CHAN WT, MERZENICH MM: Cortical remodelling induced by activity of ventral tegmental dopamine neurons. Nature 412: 79-83, 2001. https://doi.org/10.1038/35083586

BATHELLIER B, USHAKOVA L, RUMPEL S: Discrete neocortical dynamics predict behavioral categorization of sounds. Neuron 76: 435-449, 2012. https://doi.org/10.1016/j.neuron.2012.07.008

BIESZCZAD KM, WEINBERGER NM: Representational gain in cortical area underlies increase of memory strength. Proc Natl Acad Sci U S A 107: 3793-3798, 2010. https://doi.org/10.1073/pnas.1000159107

BLANCHARD DC: Translating dynamic defense patterns from rodents to people. Neurosci Biobehav Rev 76: 22-28, 2017. https://doi.org/10.1016/j.neubiorev.2016.11.001

BRADLEY MM: Natural selective attention: Orienting and emotion. Psychophysiology 46: 1-11, 2009. https://doi.org/10.1111/j.1469-8986.2008.00702.x

CHEN TW, WARDILL TJ, SUN Y, PULVER SR. RENNINGER SL, BAOHAN A, SCHREITER ER, KERR RA, ORGER MB, JAYARAMAN V, LOOGER LL, SVOBODA K, KIM DS: Ultrasensitive fluorescent proteins for imaging neuronal activity. Nature 499: 295-300, 2013. https://doi.org/10.1038/nature12354

COHEN L, MIZRAHI A: Plasticity during motherhood: changes in excitatory and inhibitory layer $2 / 3$ neurons in auditory cortex. J Neurosci 35: 1806-1815, 2015. https://doi.org/10.1523/JNEUROSCI.1786-14.2015

DIAMOND DM, WEINBERGER NM: Classical-conditioning rapidly induces specific changes in frequency receptivefields of single neurons in secondary and ventral ectosylvian auditory cortical fields. Brain Res 372: 357-360, 1986. https://doi.org/10.1016/0006-8993(86)91144-3

EDELINE JM, PHAM P, WEINBERGER NM: Rapid development of learning-induced receptive-field plasticity in the auditory-cortex. Behav Neurosci 107: 539-551, 1993. https://doi.org/10.1037/0735-7044.107.4.539

FRITZ J, SHAMMA S, ELHILALI M, KLEIN D: Rapid task-related plasticity of spectrotemporal receptive fields in primary auditory cortex. Nat Neurosci 6: 1216-1223, 2003. https://doi.org/10.1038/nn1141

FRITZ JB, DAVID SV, RADTKE-SCHULLER S, YIN P, SHAMMA SA: Adaptive, behaviorally gated, persistent encoding of task-relevant auditory information in ferret frontal cortex. Nat Neurosci 13: 1011-1119, 2010. https://doi.org/10.1038/nn.2598

FROEMKE RC, CARCEA I, BARKER AJ, YUAN K, SEYBOLD BA, MARTINS ARO, ZAIKA N, BERNSTEIN H, WACHS M, LEVIS PA, POLLEY DB, MERZENICH MM, SCHREINER CE: Long-term modification of cortical synapses improves sensory perception. Nat Neurosci 16: 79-88, 2013. https://doi.org/10.1038/nn.3274

FROEMKE RC, MERZENICH MM, SCHREINER CE: A synaptic memory trace for cortical receptive field plasticity. Nature 450: 425-429, 2007. https://doi.org/10.1038/nature06289 
FROEMKE RC, SCHREINER CE: Synaptic plasticity as a cortical coding scheme. Curr Opin Neurobiol 35: 185-199, 2015. https://doi.org/10.1016/j.conb.2015.10.003

GREWE BF, GRUNDEMANN J, KITCH LJ, LECOQ JA, PARKER JG, MARSHALL JD, LARKIN MC, JERCOG PE, GRENIER F, LI JZ, LÜTHI A, SCHNITZER MJ: Neural ensemble dynamics underlying a long-term associative memory. Nature 543: 670-675, 2017. https://doi.org/10.1038/nature21682

GREWE BF, LANGER D, KASPER H, KAMPA BM, HELMCHEN F: High-speed in vivo calcium imaging reveals neuronal network activity with near-millisecond precision. Nat Methods 7: 399-405, 2010. https://doi.org/10.1038/nmeth.1453

GUO F, INTSKIRVELI I, BLAKE DT, METHERATE R: Tone-detection training enhances spectral integration mediated by intracortical pathways in primary auditory cortex. Neurobiol Learn Mem 101: 75-84, 2013. https://doi.org/10.1016/j.nlm.2013.01.006

GUO W, CHAMBERS AR, DARROW KN, HANCOCK KE, SHINN-CUNNINGHAM BG, POLLEY DB: Robustness of cortical topography across fields, laminae, anesthetic states, and neurophysiological signal types. J Neurosci 32: 9159-9172, 2012. https://doi.org/10.1523/JNEUROSCI.0065-12.2012

HANGYA B, RANADE SP, LORENC M, KEPECS A: Central cholinergic neurons are rapidly recruited by reinforcement feedback. Cell 162: 1155-1168, 2015. https://doi.org/10.1016/j.cell.2015.07.057

HARRIS KD, QUIROGA RQ, FREEMAN J, SMITH SL: Improving data quality in neuronal population recordings. Nat Neurosci 19: 1165-1174, 2016. https://doi.org/10.1038/nn.4365

ISSA JB, HAEFFELE BD, AGARWAL A, BERGLES DE, YOUNG ED, YUE DT: Multiscale optical Ca2+ imaging of tonal organization in mouse auditory cortex. Neuron 83: 944-959, 2014. https://doi.org/10.1016/j.neuron.2014.07.009

JI WQ, SUGA N: Serotonergic modulation of plasticity of the auditory cortex elicited by fear conditioning. J Neurosci 27 : 4910-4918, 2007. https://doi.org/10.1523/JNEUROSCI.5528-06.2007

JIANG XL, SHEN S, CADWELL CR, BERENS P, SINZ F, ECKERT AS, PATEL S, TOLIAS AS: Principles of connectivity among morphologically defined cell types in adult neocortex. Science 350: aac9462, 2015. https://doi.org/10.1126/science.aac9462

KANOLD PO, NELKEN I, POLLEY DB: Local versus global scales of organization in auditory cortex. Trends Neurosci 37: 502-510, 2014. https://doi.org/10.1016/j.tins.2014.06.003

KATO HK, GILLET SN, ISAACSON JS: Flexible sensory representations in auditory cortex driven by behavioral relevance. Neuron 88: 1027-1039, 2015. https://doi.org/10.1016/j.neuron.2015.10.024

KEPECS A, FISHELL G: Interneuron cell types are fit to function. Nature 50: 318-326, 2014. https://doi.org/10.1038/nature12983

KILGARD MP, MERZENICH MM: Cortical map reorganization enabled by nucleus basalis activity. Science 279: 1714-1718, 1998. https://doi.org/10.1126/science.279.5357.1714

KONG E, MONJE FJ, HIRSCH J, POLLAK DD: Learning not to fear: neural correlates of learned safety. Neuropsychopharmacology 39: 515-527, 2014. https://doi.org/10.1038/npp.2013.191

KRABBE S, PARADISO E, D'AQUIN S, BITTERMAN Y, COURTIN, XU C, YONEHARA K, MARKOVIC M, MÜLLER C, EICHLISBERGER T, GRÜNDEMANN J, FERRAGUTI F, LÜTHI A: Adaptive disinhibitory gating by VIP interneurons permits associative learning. Nat Neurosci 22: 1834-1843, 2019. https://doi.org/10.1038/s41593-019-0508-y

KRAUS N, DISTERHOFT JF: Response plasticity of single neurons in rabbit auditory association cortex during tonesignalled learning. Brain Res 246: 205-215, 1982. https://doi.org/10.1016/0006-8993(82)91168-4

KUCHIBHOTLA KV, GILL JV, LINDSAY GW, PAPADOYANNIS ES, FIELD RE, HINDMARSH STEN TA, MILLER KD, FROEMKE RC: Parallel processing by cortical inhibition enables context-dependent behavior. Nat Neurosci 20: 62-71, 2017. https://doi.org/10.1038/nn.4436

LAI CSW, FRANKE TF, GAN WB: Opposite effects of fear conditioning and extinction on dendritic spine remodelling. Nature 483: 87-91, 2012. https://doi.org/10.1038/nature10792

LAKATOS P, MUSACCHIA G, O'CONNEL MN, FALCHIER AY, JAVITT DC, SCHROEDER CE: The spectrotemporal filter mechanism of auditory selective attention. Neuron 77: 750-761, 2013. https://doi.org/10.1016/j.neuron.2012.11.034 
LAKUNINA AA, NARDOCI MB, AHMADIAN Y, JARAMILLO S: Somatostatin-expressing interneurons in the auditory cortex mediate sustained suppression by spectral surround. J Neurosci 40: 3564-3575, 2020. https://doi.org/10.1523/JNEUROSCI.1735-19.2020

LEE S, KRUGLIKOV I, HUANG ZJ, FISHELL G, RUDY B: A disinhibitory circuit mediates motor integration in the somatosensory cortex. Nat Neurosci 16: 1662-1670, 2013. https://doi.org/10.1038/nn.3544

LETZKUS JJ, WOLFF SBE, LUTHI A: Disinhibition, a circuit mechanism for associative learning and memory. Neuron 88: 264-276, 2015. https://doi.org/10.1016/j.neuron.2015.09.024

LETZKUS JJ, WOLFF SBE, MEYER EMM, TOVOTE P, COURTIN J, HERRY C, LÜTHI A: A disinhibitory microcircuit for associative fear learning in the auditory cortex. Nature 480: 331-335, 2011. https://doi.org/10.1038/nature10674

LI L-Y, XIONG XR, IBRAHIM LA, YUAN W, TAO HW, ZHANG LI: Differential receptive field properties of parvalbumin and somatostatin inhibitory neurons in mouse auditory cortex. Cereb Cortex 25: 1782-1791, 2014. https://doi.org/10.1093/cercor/bht417

LI LY, JI XY, LIANG FX, LI YT, XIAO Z, TAO HW, ZHANG LI: A feedforward inhibitory circuit mediates lateral refinement of sensory representation in upper layer $2 / 3$ of mouse primary auditory cortex. J Neurosci 34 : 13670-13683, 2014. https://doi.org/10.1523/JNEUROSCI.1516-14.2014

LIU BH, WU GK, ARBUCKLE R, TAO HW, ZHANG LI: Defining cortical frequency tuning with recurrent excitatory circuitry. Nat Neurosci 10: 1594-1600, 2007. https://doi.org/10.1038/nn2012

MAOR I, SHALEV A, MIZRAHI A: Distinct spatiotemporal response properties of excitatory versus inhibitory neurons in the mouse auditory cortex. Cereb Cortex 26: 4242-4252, 2016. https://doi.org/10.1093/cercor/bhw266

MARLIN BJ, MITRE M, D'AMOUR JA, CHAO MV, FROEMKE RC: Oxytocin enables maternal behaviour by balancing cortical inhibition. Nature 520: 499-504, 2015. https://doi.org/10.1038/nature14402

MCGANN JP: Associative learning and sensory neuroplasticity: how does it happen and what is it good for? Learn Mem 22: 567-576, 2015. https://doi.org/10.1101/1m.039636.115

MOCZULSKA KE, TINTER-THIEDE J, PETER M, USHAKOVA L, WERNLE T, BATHELLIER B, RUMPEL S: Dynamics of dendritic spines in the mouse auditory cortex during memory formation and memory recall. Proc Natl Acad Sci U S A 110: 18315-18320, 2013. https://doi.org/10.1073/pnas.1312508110

NAKAYAMA D, BARAKI Z, ONOUE K, IKEGAYA Y, MATSUKI N, NOMURA H: Frontal association cortex is engaged in stimulus integration during associative learning. Curr Biol 25: 117-123, 2015. https://doi.org/10.1016/j.cub.2014.10.078

NODA T, TAKAHASHI H: Anesthetic effects of isoflurane on the tonotopic map and neuronal population activity in the rat auditory cortex. Eur J Neurosci 42: 2298-2311, 2015. https://doi.org/10.1111/ejn.13007

NOVAK O, ZELENKA O, HROMADKA T, SYKA J: Immediate manifestation of acoustic trauma in the auditory cortex is layer-specific and cell type-dependent. J Neurophysiol 115: 1860-1874, 2016. https://doi.org/10.1152/jn.00810.2015

PACHITARIU M, LYAMZIN DR, SAHANI M, LESICA NA: State-dependent population coding in primary auditory cortex. J Neurosci 35: 2058-2073, 2015. https://doi.org/10.1523/JNEUROSCI.3318-14.2015

PI HJ, HANGYA B, KVITSIANI D, SANDERS JI, HUANG ZJ, KEPECS A: Cortical interneurons that specialize in disinhibitory control. Nature 503: 521-524, 2013. https://doi.org/10.1038/nature12676

PIENKOWSKI M, EGGERMONT JJ: Cortical tonotopic map plasticity and behavior. Neurosci Biobehav Rev 35 : 2117-2128, 2011. https://doi.org/10.1016/j.neubiorev.2011.02.002

POLLEY DB, STEINBERG EE, MERZENICH MM: Perceptual learning directs auditory cortical map reorganization through top-down influences. J Neurosci 26: 4970-4982, 2006. https://doi.org/10.1523/JNEUROSCI.3771$\underline{05.2006}$

POORT J, KHAN AG, PACHITARIU M, NEMRI A, ORSOLIC I, KRUPIC J, BAUZA M, SAHANI M, KELLER GB, MRSIC-FLOGEL TD, HOFER SB: Learning enhances sensory and multiple non-sensory representations in primary visual cortex. Neuron 86: 1478-1490, 2015. https://doi.org/10.1016/j.neuron.2015.05.037

RECANZONE GH, SCHREINER CE, MERZENICH MM: Plasticity in the frequency representation of primary auditory-cortex following discrimination-training in adult owl monkeys. J Neurosci 13: 87-103, 1993. https://doi.org/10.1523/JNEUROSCI.13-01-00087.1993 
RODGERS CC, DEWEESE MR: Neural correlates of task switching in prefrontal cortex and primary auditory cortex in a novel stimulus selection task for rodents. Neuron: 1157-1170, 2014. https://doi.org/10.1016/j.neuron.2014.04.031

ROTHSCHILD G, COHEN L, MIZRAHI A, NELKEN I: Elevated correlations in neuronal ensembles of mouse auditory cortex following parturition. J Neurosci 33: 12851-12861, 2013. https://doi.org/10.1523/JNEUROSCI.4656-12.2013

ROTHSCHILD G, MIZRAHI A: Global order and local disorder in brain maps. Annu Rev Neurosci 38: $247-268$, 2015. https://doi.org/10.1146/annurev-neuro-071013-014038

ROTHSCHILD G, NELKEN I, MIZRAHI A: Functional organization and population dynamics in the mouse primary auditory cortex. Nat Neurosci 13: 353-360, 2010. https://doi.org/10.1038/nn.2484

RUTKOWSKI RG, WEINBERGER NM: Encoding of learned importance of sound by magnitude of representational area in primary auditory cortex. Proc Natl Acad Sci U S A 102: 13664-13669, 2005. https://doi.org/10.1073/pnas.0506838102

SARRO EC, VON TRAPP G, MOWERY TM, KOTAK VC, SANES DH: Cortical synaptic inhibition declines during auditory learning. J Neurosci 35: 6318-6325, 2015. https://doi.org/10.1523/JNEUROSCI.4051-14.2015

SCHREINER CE, POLLEY DB: Auditory map plasticity: diversity in causes and consequences. Curr Opin Neurobiol 24: 143-156, 2014. https://doi.org/10.1016/j.conb.2013.11.009

SHEPARD KN, CHONG KK, LIU RC: Contrast enhancement without transient map expansion for species-specific vocalizations in core auditory cortex during learning. eNeuro 3: 1-13, 2016. https://doi.org/10.1523/ENEURO.0318$\underline{16.2016}$

SVOBODA K, YASUDA R: Principles of two-photon excitation microscopy and its applications to neuroscience. Neuron 50: 823-839, 2006. https://doi.org/10.1016/j.neuron.2006.05.019

SYKA J: Plastic changes in the central auditory system after hearing loss, restoration of function, and during learning. Physiol Rev 82: 601-636, 2002. https://doi.org/10.1152/physrev.00002.2002

TAKEMOTO M, SONG WJ: Cue-dependent safety and fear learning in a discriminative auditory fear conditioning paradigm in the mouse. Learn Mem 26: 284-290, 2019. https://doi.org/10.1101/lm.049577.119

TOMEK J, NOVAK O, SYKA J: Two-Photon Processor and SeNeCA: a freely available software package to process data from two-photon calcium imaging at speeds down to several milliseconds per frame. J Neurophysiol 110 : 243-256, 2013. https://doi.org/10.1152/jn.00087.2013

TREMBLAY R, LEE S, RUDY B: GABAergic Interneurons in the neocortex: from cellular properties to circuits. Neuron 91: 260-292, 2016. https://doi.org/10.1016/j.neuron.2016.06.033

WEINBERGER NM: Associative representational plasticity in the auditory cortex: A synthesis of two disciplines. Learn Mem 14: 1-16, 2007. https://doi.org/10.1101/1m.421807

WINKOWSKI DE, BANDYOPADHYAY S, SHAMMA SA, KANOLD PO: Frontal cortex activation causes rapid plasticity of auditory cortical processing. J Neurosci 33: 18134-18148, 2013. https://doi.org/10.1523/JNEUROSCI.0180-13.2013

YIN PB, FRITZ JB, SHAMMA SA: Rapid spectrotemporal plasticity in primary auditory cortex during behavior. J Neurosci 34: 4396-4408, 2014. https://doi.org/10.1523/JNEUROSCI.2799-13.2014

ZHANG SY, XU M, KAMIGAKI T, DO JPH, CHANG W-C, JENWAY S, MIYAMICHI K, LUOL, DAN Y: Longrange and local circuits for top-down modulation of visual cortex processing. Science 345: 660-665, 2014. https://doi.org/10.1126/science.1254126 